\title{
Meconium aspiration: Case report
}

\author{
Marinković $\mathrm{N}^{*}$ and Aleksić I \\ Faculty of Medicine of the Military Medical Academy, University of Defence, Belgrade
}

\begin{abstract}
Introduction: Aspiration of amniotic fluid has clinical significance as a cause of disease and mortality of new-borns, but also has a forensic significance due to numerous steps that need to be determined in the establishing of medical malpractice.

Case Report: Female new-born, born in the 40th week of pregnancy by emergency C-section with green amniotic fluid. Immediately upon the C-section, without heart function, with limpness, cyanotic, without tone and reflex. Heavily aspirated with green liquid content in the apparatus, cardiopulmonary reanimation started immediately, achieved heart rhythm with bradycardia. On the X-ray image, lungs bilaterally have small grainy confluating shadows. Auscultation on the lungs shows symmetrical breathing with bilateral pops. Despite the nasal oxygen therapy, the death has occurred during transport to the appropriate medical institution. Forensic autopsy has shown no foreign content in the external nasal and oral cavities, oesophagus, trachea and bronchi are free from foreign content. Lung tissue with reduced aeration, with flat, medium bloody cross-section with red spots; when pressure is exerted, no content comes out from the bronchi. Pathohistological examination of tissue taken during autopsy has shown the presence of foreign content in the alveoli and bronchi, mostly consisting of squamous cells and mucus, with occasional dark irregular grainy formations, fresh bleeding and presence of neutrophils in alveolar area (HE, Alcian blue, Pan cytokeratin). Based on the autopsy results, data from the medical documents and chemical-toxicological analysis, it has been concluded that this was a violent death caused by asphyxiation due to aspiration of amniotic fluid and meconium.
\end{abstract}

Conclusion: There are still different approaches to prevention and treatment of meconium aspiration syndrome, and thus research should continue to reduce morbidity and mortality and facilitate forensic expertise in procedures to prove malpractice.

\section{Introduction}

Aspiration of amniotic fluid with meconium represents one of the causes of disease and mortality of new-borns, but also poses one of the problems for forensic expertise in malpractice cases. The frequency of meconium presence in amniotic fluid is $5-22 \%$, the aspiration of amniotic fluid occurs in around $10-15 \%$ new-borns, where $2-10$ $\%$ of them develop meconium aspiration syndrome [1-5]. Meconium aspiration syndrome is defined as a respiratory distress in new-borns due to aspiration of amniotic fluid containing meconium, with the characteristic $\mathrm{x}$-ray findings in the lungs, but without other cause [6]. The first description of meconium aspiration and meconium aspiration syndrome dates back from 1918 [7].

\section{Case Report}

Female new-born, born in the 40th week of pregnancy by emergency C-section. Amniotic fluid was green, umbilical cord was wrapped around the neck 3 times. Body weight at birth $2700 \mathrm{~g}$, length $47 \mathrm{~cm}$, head circumference $30 \mathrm{~cm}$, Apgar 1/3. Immediately upon the C-section, without heart function, with limpness, cyanotic, without tone and reflex. Heavily aspirated with green liquid content in the apparatus, cardiopulmonary reanimation started immediately, achieved heart rhythm with bradycardia. On the X-ray image, lungs bilaterally have small grainy confluating shadows. Auscultation on the lungs shows symmetrical breathing with bilateral pops. Nasal oxigenotherapy has been ordered and the new-born was transported to a regional health institution where gas analysis have shown the following results: CO2 $8.09 \mathrm{kPa}, \mathrm{O} 26.4 \mathrm{kPa}, \mathrm{HCO} 20.9 \mathrm{mmol} / \mathrm{L}, \mathrm{pH}$ 6.9. Nasal oxygenotherapy was continued, but respiratory weakness has progressively developed, and thus it was decided for the new-born to be transported to a specialized paediatric institution; however, death has occurred during transport, 12 hours after birth.

Forensic autopsy has been carried out and the following was concluded: the umbilical cord stump around $0.6 \mathrm{~cm}$ long, firmly tied with plasticized dark-blue and black thread, the stump was dry, without secretion, with usual colour. On the skin on the front side of the neck, a sidelong stripe, difficult to notice, around $7 \mathrm{~cm}$ long, $2 \mathrm{~cm}$ wide, pale, wet. No foreign content was found in the external nasal and oral cavities. Nails on fingers and toes are purple, go beyond the pads of the fingers. The scalp tissue is wet, medium bloody, with localized surface petechial collections and with circular dark red haemorrhage on the right half of the frontal part with diameter of $2 \mathrm{~cm}$ and thickness of $0.4 \mathrm{~cm}$. The tissue of the cerebellum and cerebrum, pons, medulla oblongata and spinal cord is mildly soft, with clear structure, cerebral cortex and grey matter distinguished from the white centre. Preparation of the skin, subcutaneous tissue, muscles and large blood vessels in the neck have been done and no injuries have been found. The oesophagus has no foreign content, mucous membrane normally wrinkled, medium bloody. No content in the trachea and bronchi, mucous membrane smooth and medium bloody. The chest cavity has no foreign content. Both lungs are free.

${ }^{\star}$ Correspondence to: Nadica Marinković, Faculty of Medicine of the Military Medical Academy, University of Defence, Belgrade, Tel: +381646361415; E-mail: nadicamarinkovic@yahoo.com

Key words: new-born, meconium aspiration, hypoxia, ventilation

Received: October 15, 2018; Accepted: October 22, 2018; Published: October 29, 2018 
Reduced aeration of the lung tissue, with flat medium bloody reddish ecchymosis on the cross-section, no content comes out from the bronchi when pressure is exerted. Epicard has dark red petechial spots and ecchymosis. Air present in the stomach, no other content, mucous membrane levelled, medium bloody. Green liquid content present in the small intestine and colon, mucous membrane smooth, medium bloody.

Pathohistological examination of tissue taken during autopsy has shown the presence of foreign content in the alveoli and bronchi, mostly consisting of squamous cells and mucus, with occasional dark irregular grainy formations, fresh bleeding and presence of neutrophils in alveolar area (HE, Alcian blue, Pan cytokeratin) (Figure 1). Fresh haemorrhage has been found below the epicard and pelvis renalis. Based on the autopsy results, data from the medical documents and chemical-toxicological analysis, it has been concluded that this was a violent death caused by asphyxiation due to aspiration of amniotic fluid and meconium.

\section{Discussion}

The meconium, bowel content in a new-born child, contains 72-80 $\%$ water, desquamated skin and bowel cells, gastrointestinal mucous, lanugo hair, vernix caseosa, amniotic fluid, cholesterol and pancreatic enzymes [8]. The main cause of meconium aspiration is asphyxiation of the neonate leading to the release of meconium and gasping inspiration. The causes of asphyxiation are placental insufficiency, hypertension and diabetes mellitus of the mother, preeclampsia and eclampsia, amniotic fluid deficiency, use of substances of abuse by the mother, in particular tobacco and cocaine, infection of the mother, chorioamnionitis, and on the side of the neonate lung hypoplasia or aplasia, respiratory system anomaly, anomalies of the diaphragm and alike [1]. There is also a theory that the pressure of the umbilical cord on the neck of the foetus causes vagal response [9]. The frequency of meconium in the amniotic fluid increases with the length of pregnancy, and thus in the 37th week it is $3 \%$, in the 40 th week it is $13 \%$, while it is extremely rare in preterm new-borns, which is explained by immaturity of the digestive tract and the deficiency of the intestinal peptide that is crucial for the start of peristalsis [10]. Other than the presence of meconium in airways, other signs of meconium aspiration syndrome include discoloration of umbilical cord that occurs after 15 minutes, if the meconium is thick, if it is not after one hour, and discoloration of nails that occurs after 4-6 hours [1].

Pathophysiological mechanism that completely or partially closes the small airways with aspirated meconium explains the development of atelectasis or expansion of the alveolar space and emphysema. Meconium, however, may cause toxic damage of lung tissue, surfactant inactivation and inflammation [11]. Fetal pancreatic enzymes in the meconium may cause lung tissue digestion [12]. Meconium acts proinflammatory and stimulates production of interleukins (IL-1, IL-6, IL-8) which have chemotactic effect on inflammatory cells, neutrophils

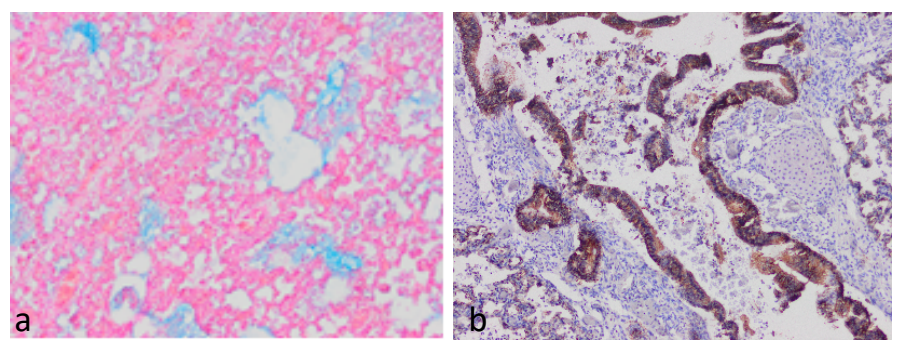

Figure 1. Foreign content in the alveoli and bronchi (Alcian blue-a, Pan cytokeratin-b) and macrophage. These may be found in alveoli, major airways and lung tissue of the new-borns with meconium aspiration syndrome, and the result is chemical inflammation, lung tissue damage, but also the occurrence of bacterial inflammation of lung tissue with multiple organ damage $[4,13]$.

Treatment and therapy of the new-born with meconium aspiration have changed and adapted over the decades. A forensic problem of meconium aspiration is significant, due to the increased risk of malpractice lawsuits in the event of death of a new-born due to meconium aspiration or consequences thereof, and before most due to damage of the CNS caused by hypoxia in surviving new-borns. Lawsuits are directed towards gynaecologist obstetricians, who were in charge of the pregnancy, but also towards neonatologists. Forensic expertise in these cases, in addition to the adequately kept medical documents, is facilitated by the existence of regularly updated protocols in gynaecology and particularly in neonatology, which clearly determine the most advanced therapeutic procedures [14,15] and thus protect both the patients and doctors before the court. Therapeutic procedures proclaimed during the 1970 s by Bonita Carson prescribe that in the event of intrauterine evacuation of meconium oropharyngeal suction should be done immediately upon crowning, followed by larynx exploration and endotracheal intubation upon the completion of childbirth if the meconium is found at the level of vocal cords [16]. Since 2006, ILCOR (International Liaison Committee on Resuscitation) recommends that the oropharyngeal suction is not mandatory immediately upon crowing, except in cases where there is a significant risk of a severe form of meconium aspiration syndrome, in childbirth induction, C-section due to fetal distress or Apgar score in 1st minute $\leq 3$ [17]. The treatment of severe forms of MAS implies mechanical ventilation. Other that the mechanical ventilation, the therapy of choice includes antibiotics, corticosteroids and exogenous surfactants, since the secondary deficit of surfactant plays a significant role in the pathogenesis of MAS, and the corticosteroids act on inflammatory processes in case of MAS and may contribute to the synthesis of surfactant [5]. Oropharyngeal suction does not guarantee successful treatment, and thus in the presented case, oropharyngeal suction has been done after childbirth, the content from the upper airways was eliminated and it was not present in the trachea and bronchi during autopsy, but the histological examination of the tissue has shown the presence in alveoli and smaller branches of bronchi. The significance of timely diagnosis and adequate therapy is presented in the paper analysing a total of 198 cases of newborns with meconium aspiration syndrome during the period of nine years. The analysed cases did not include a single fatality, however, there were pulmonary hypertensions in 14 cases, pneumothorax in 11 cases, lung haemorrhage in one case and neurological damage and Broncho pulmonary dysplasia in two cases each, and thus it was shown that adequate traning of the medical staff for neonatal reanimation accompanied by high frequency respiration, which may slow down the progression of meconium down the tracheobronchial tree, with the use of NO when there is no reaction to standard therapy, may reduce the morbidity and mortality even without extracorporeal membrane oxygenation [18]. Some authors claim that high frequency oscillation ventilation is not a good treatment method for new-borns with meconium aspiration, except in cases of morphological damage to the lung tissue, since the active expiration results in a collapse of small airways around the meconium plug and the air is retained distally [1]. Various ventilation strategies are used depending of the severity of disease and complications, with the aim to ensure gas exchange and prevent overfilling of lung segments due to blockage of air in the airways, which is more easily achieved if the ventilation is done with 
lower frequency with a longer expiration time. If all other ventilation methods fail, extracorporeal mechanical ventilation is used.

\section{Conclusion}

Meconium aspiration syndrome, with the overall therapeutic treatment, in a certain number of new-borns may lead to death. As a preventive measure, pregnant women with increased risk of hypoxic fetal distress should be monitored. In the event of aspiration, adequate artificial ventilation as a treatment of choice should be ensured in all institutions where there is a maternity ward, however, major differences are evident in the development of the health institutions and the level of equipment in health institutions in different parts of the world. In addition, there are still different approaches to prevention and treatment of meconium aspiration syndrome, and thus research should continue to reduce morbidity and mortality and facilitate forensic expertise in procedures to prove malpractice.

\section{References}

1. Hachey WE (2009) Meconium Aspiration: Neonatology, Management, Procedures, On-Call Problems, Diseases and Drugs, (6thedn), The Mc Graw-Hill; USA, 574-9.

2. Emmerson AJB (2014) Predictors of Mortality in Neonates with Meconium Aspiration Syndrome. Indian Pediatr 51: 610-1. [Crossref]

3. Shaika M, Waheed KAI, Javaid S, Gul R, Hashmi AM (2016) Detrimental complications of meconium aspiration syndrome and their impact on outcome. J Eyub Med Coll Abbottabad 28: 506-9. [Crossref]

4. Fanaroff AA (2008) Meconium aspiration syndrome: historical aspects. J Perinatol 28: 53-7. [Crossref]

5. Swarnam K, Soraisham AS, Sivanandan S (2012) Advances in the management of meconium aspiration syndrome. Int J Pediatr 2012: 359571. [Crossref]
6. Raju U, Sondhi V, Patnaik SK (2010) Meconium Aspiration Syndrome: An Insight. Med J Armed Forces India 66: 152-157. [Crossref]

7. Alonso-Spilsbury M, Mota-Rojas D, Villanueva-García D, Martínez-Burnes J, Orozco $\mathrm{H}$, et al. (2005) Perinatal asphyxia pathophysiology in pig and human: a review. Anim Reprod Sci 90: 1-30. [Crossref]

8. Wiswell TE, Bent RC (1993) Meconium staining and the meconium aspiration syndrome: unresolved issues. Pediatr Clin North Am 50: 955-81. [Crossref]

9. Miller FC, Read JA (1981) Intrapartum assessment of the postdate fetus. Am J Obstet Gynecol 141: 516-520. [Crossref]

10. Mardešic D, et al (2003) Pedijatrija, Zagreb, Školska knjiga.

11. Kopincova J, Calkovska A (2016) Meconium-induced inflammation and surfactan inactivation: specifics of molecular mechanisms. Pediatr Res 79: 514-521. [Crossref]

12. Ivanov VA, Gewoib IH, Uhal BD (2010) A new look at the pathogenesis of the meconium aspiration syndrome: a role of fetal pancreatic proteolytic enzymes in epithelial cell detachment. Pediatr Res 68: 221-224. [Crossref]

13. Cleary GM, Wiswell TE (1998) Meconium - stained amniotic fluid and the meconium aspiration syndrome: un update. Pediatr Clin North Am 45: 511-529. [Crossref]

14. Ilic S, Pejovic B (2003) Protokoli u neonatologiji, Institut za neonatologiju Beograd.

15. Duke M (2017) Clinical Guidelines for the management of newborn babies born to wothers with meconium stained liquor. Norfolk and Norwich uviversity hospitals

16. Carson BS, Losey RW, Bowes WA, Simmons MA (1976) Combined obstetric and pediatric approach to prevent meconium aspiration syndrome. Am J Obstet Gynecol 126: 712-5. [Crossref]

17. International Liaison Committee on Resuscitation (2006) The International Liaison Committee on Resuscitation (ILCOR) consensus on science with treatment recommendations for pediatric and neonatal patients: pediatric basic and advanced life support. Pediatrics 117: e955-977. [Crossref]

18. Lin HC, Su BH, Lin TW, Tsai CH, Ysh TF (2005) System - based strategy for the management of meconium aspiration syndrome 198 consecutive cases observations. Acta Paediatr Taiwan 46: 67-71. [Crossref]

Copyright: (C2018 Marinković N. This is an open-access article distributed under the terms of the Creative Commons Attribution License, which permits unrestricted use, distribution, and reproduction in any medium, provided the original author and source are credited. 